\title{
Patterns and risk of recurrence in patients with esophageal cancer with a pathologic complete response after chemoradiotherapy followed by surgery
}

\author{
Arianna Barbetta, MD, ${ }^{\mathrm{a}}$ Smita Sihag, MD, ${ }^{\mathrm{a}}$ Tamar Nobel, MD, ${ }^{\mathrm{a}}$ Meier Hsu, MS, ${ }^{\mathrm{b}}$ Kay See Tan, PhD, \\ Manjit Bains, MD, ${ }^{\mathrm{a}}$ David R. Jones, MD, ${ }^{\mathrm{a}}$ and Daniela Molena, $\mathrm{MD}^{\mathrm{a}}$
}

\section{ABSTRACT}

Objectives: A pathologic complete response in patients with locally advanced esophageal cancer after chemoradiotherapy and surgery is associated with improved overall and disease-free survival. Nevertheless, approximately one third of patients with a pathologic complete response still have a recurrence. The aim of this study was to evaluate risk factors and patterns of recurrence in patients with locally advanced esophageal cancer who achieved a pathologic complete response after chemoradiotherapy and surgery.

Methods: We performed a retrospective review of a single-institution database of 233 patients with stage II and III esophageal cancer with a pathologic complete response after chemoradiotherapy and surgery between 1997 and 2017. A multivariable competing risk-regression model was used to identify predictors of recurrence.

Results: A total of 61 patients exhibited recurrence in this cohort, 43 with adenocarcinoma and 18 with squamous cell carcinoma. Five-year cumulative incidence of recurrence did not vary by histology. Univariable analysis revealed that poor tumor differentiation (hazard ratio, 2.28; $P=.022$ ) and advanced clinical stage (hazard ratio, $1.89 ; P=.042$ ) are predictors of recurrence in the esophageal adenocarcinoma subgroup, whereas poor tumor differentiation remained the only independent predictor on multivariable analysis in the entire cohort (hazard ratio, 2.28; $P=.009$ ). Patients with esophageal adenocarcinoma had a higher incidence of distant recurrences, and patients with esophageal squamous cell carcinoma demonstrated a higher incidence of loco-regional recurrence $(P=.039)$.

Conclusions: Poor tumor differentiation is an independent risk factor for recurrence in patients with esophageal cancer with a pathologic complete response. Although there is no difference in the cumulative incidence of recurrence between esophageal adenocarcinoma and esophageal squamous cell carcinoma, patterns of recurrence appear to differ. Thus, treatment and surveillance strategies may be tailored appropriately. (J Thorac Cardiovasc Surg 2019;157:1249-59)

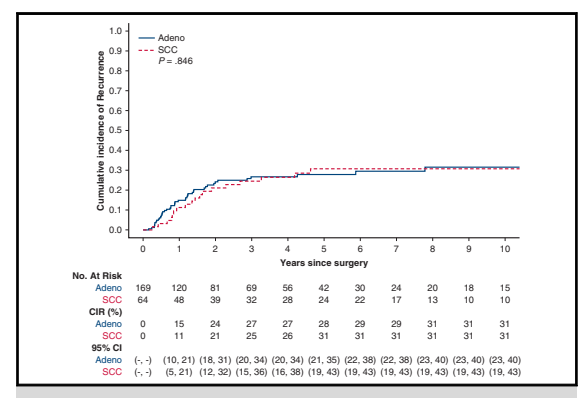

CIR after pCR, by histology.

Central Message

Although risk factors and the CIR after a pCR to chemoradiotherapy plus surgery do not vary by histology, patterns of recurrence appear to differ.

\section{Perspective}

Few studies have examined recurrence patterns in patients with complete pathologic response after trimodality therapy with comparison by histology. Although the rate of long-term cure is higher in this cohort, our study suggests patients with poorly differentiated tumors have a higher recurrence rate and perhaps should undergo more aggressive surveillance during the initial 2-year period after treatment in accordance to histologic subtype.

See Commentaries on pages 1260 and 1262.

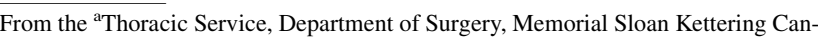
cer Center, New York, NY; and ${ }^{b}$ Department of Epidemiology and Biostatistics, Memorial Sloan Kettering Cancer Center, New York, NY.

A.B. and S.S. contributed equally to this article.

This study was supported, in part, by National Institutes of Health/National Cancer Institute Cancer Center Support Grant P30 CA008748. A.B. is supported by a Surgeon Development award from the Esophageal Cancer Education Foundation. Institutional Review Board approval: Protocol \#16-1631 conditionally approved July 21, 2016, approved December 13, 2016.

Read at the 98th Annual Meeting of The American Association for Thoracic Surgery, San Diego, California, April 28-May 1, 2018.

Received for publication May 2, 2018; revisions received Sept 7, 2018; accepted for publication Sept 22, 2018; available ahead of print Jan 14, 2019.

Address for reprints: Daniela Molena, MD, Thoracic Service, Department of Surgery, Memorial Sloan Kettering Cancer Center, 1275 York Ave, C-873, New York, NY 10065 (E-mail: molenad@mskcc.org).

$0022-5223 / \$ 36.00$

Copyright (c) 2018 by The American Association for Thoracic Surgery

https://doi.org/10.1016/j.jtcvs.2018.09.136
}

Neoadjuvant chemoradiotherapy plus surgery (CRT-S) has been widely established as standard of care for patients with locally advanced esophageal cancer. This tri-modal approach has been shown to facilitate radical resection and improve both overall survival (OS) and disease-free

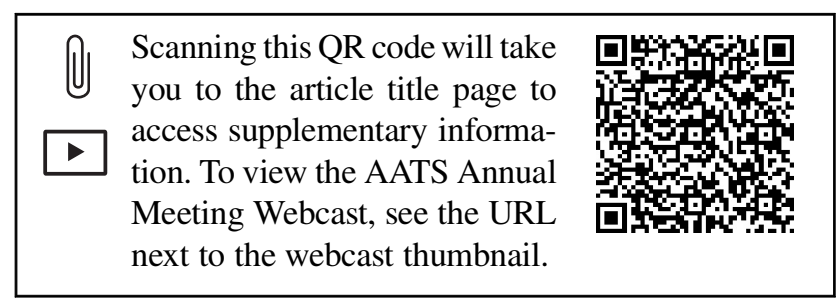




$$
\begin{aligned}
& \text { Abbreviations and Acronyms } \\
& \text { CIR = cumulative incidence of recurrence } \\
& \text { CRT-S }=\text { neoadjuvant chemoradiotherapy plus } \\
& \text { surgery } \\
& \mathrm{CT}=\text { computed tomography } \\
& \text { DFS = disease-free survival } \\
& \text { EAC = esophageal adenocarcinoma } \\
& \mathrm{ESCC}=\text { esophageal squamous cell carcinoma } \\
& \text { IQR = interquartile range } \\
& \text { LRR = loco-regional recurrence } \\
& \text { OS = overall survival } \\
& \text { pCR = pathologic complete response } \\
& \text { PET = positron emission tomography }
\end{aligned}
$$

survival (DFS) ${ }^{1-3}$ Esophageal cancers are divided into 2 primary histologies worldwide: esophageal squamous cell carcinoma (ESCC), which is far more prevalent in Asia and developing nations, and esophageal adenocarcinoma (EAC), which accounts for the majority of cases in the United States because of increasing rates of obesity and gastroesophageal reflux disease. ${ }^{4}$ Integrated analyses from the Cancer Genome Atlas suggest distinct mutational signatures and genetic underpinnings associated with these 2 histologies, and in fact, distinct clinical outcomes in terms of treatment response and survival are similarly observed.

After CRT-S, approximately $45 \%$ of patients with ESCC and $25 \%$ of patients with EAC achieve a pathologic complete response (pCR), defined as no histologic evidence of tumor in the surgical specimen. ${ }^{1,6}$ The degree of response to chemoradiotherapy is a strong predictor of both OS and DFS, and several studies have demonstrated that patients with a pCR have better OS and DFS and lower rates of recurrence in comparison with patients with residual disease contained in the surgical specimen despite complete resection..$^{7-9}$ In particular, for patients with pCR, 5 -year OS and DFS have been reported to be approximately $50 \%$ regardless of histology. ${ }^{10-13}$

Despite these positive results, $21 \%$ to $39 \%$ of patients who achieve pCR do have recurrence, predominantly within 2 years post-treatment. ${ }^{8-10}$ Whether such patients with early recurrences truly had no evidence of residual disease after CRT-S certainly remains a valid question, because misclassification of minimal residual disease is possible. However, if they were correctly designated as having a pCR, then underlying clinical characteristics and tumor biology that predispose to recurrence are worth exploring to better risk stratify patients. Although patients with ESCC do exhibit higher rates of chemosensitivity and $\mathrm{pCR}$ with lower rates of distant failure in comparison with patients with EAC, little is known about clinical factors associated with risk of disease recurrence in this unique subset of patients with
pCR, as well as the impact of histology on outcomes. Significant heterogeneity exists among the few studies that have investigated this area. For instance, Luc and colleagues ${ }^{14}$ found that EAC histology and grade 3 to 4 postoperative complications were the only clinical factors significantly associated with recurrence in patients with pCR. In another retrospective study of 70 patients with ESCC and pCR, advanced clinical tumor stage (ie, T3-4) was the only independent risk factor for recurrence. ${ }^{15}$ However, in a larger multicenter study including 299 patients with pCR, no significant clinical or pathologic risk factors for recurrence were identified. ${ }^{10}$

Understanding both the risk factors and the patterns of recurrence in patients who achieved a $\mathrm{pCR}$ can provide insight into optimization of both systemic and local therapies, as well as appropriate surveillance intervals and strategies. In fact, although it is well established that response to chemoradiation therapy affects the rate of recurrence overall, whether the site of recurrence differs between patients with and without pCR is unclear. ${ }^{7,8,11,13}$ Thus, the aim of the current study was to evaluate both risk factors and patterns of recurrence in patients who achieved $\mathrm{pCR}$ after CRT-S for locally advanced esophageal cancer. In addition, patterns of recurrence were also compared between EAC and ESCC cohorts to examine differences related to tumor histology.

\section{MATERIALS AND METHODS Study Population}

All patients with clinical stage II and III esophageal cancer treated with CRT-S who achieved pCR from 1997 to 2017 were identified using a prospectively maintained database by the Thoracic Surgery Service at Memorial Sloan Kettering Cancer Center. Patients who received neoadjuvant chemotherapy or radiotherapy alone, or salvage esophagectomy after definitive chemoradiotherapy were excluded. Patients with missing survival data and tumors of the cervical esophagus were also excluded (Figure E1). This study was reviewed and approved by our Institutional Review Board, and informed consent was waived.

\section{Variables}

The following variables were available for comparison in our study: age, sex, race, comorbidities, tumor histology, endoscopic length of tumor, pathologic length of tumor bed, length of proximal and distal margins, clinical and pathologic stage, treatment regimen, surgical complications, recurrence, and survival status. The entire pathologic specimen was submitted for pathologic examination. Tumor location was determined by the distance of proximal edge of the lesion from the incisors. The endoscopic length of the tumor was calculated when both proximal and distal edges of lesion were recorded. Clinical and pathologic stage was classified according to the 7th edition of the American Joint Committee on Cancer Staging Manual. Pretreatment staging assessment was performed using endoscopic ultrasound and computed tomography (CT) or positron emission tomography (PET) CT. All patients received concurrent neoadjuvant chemoradiation. Induction chemotherapy before chemoradiation was given to a subset of patients.

A pCR was defined as complete absence of viable tumor grossly and microscopically in the entire surgical specimen consisting of the resected esophagus and all harvested lymph nodes. ${ }^{16}$ Presence of residual lesions 
TABLE 1. Patient characteristics overall and by histology

\begin{tabular}{|c|c|c|c|c|}
\hline Characteristic & Overall $(\mathbf{N}=\mathbf{2 3 3})$ & Adenocarcinoma $(\mathrm{N}=169)$ & $\operatorname{SCC}(N=64)$ & $P$ value \\
\hline Age, $y$ & $61(56,68)$ & $61(56,69)$ & $59(55,66)$ & .153 \\
\hline Sex & & & & $<.001$ \\
\hline M & $184(79)$ & $149(88.2)$ & $35(54.7)$ & \\
\hline $\mathrm{F}$ & $49(21)$ & $20(11.8)$ & $29(45.3)$ & \\
\hline Clinical stage & & & & .449 \\
\hline II & $87(37.3)$ & $66(39.1)$ & $21(32.8)$ & \\
\hline III & $146(62.7)$ & $103(60.9)$ & $43(67.2)$ & \\
\hline Tumor location & & & & $<.001$ \\
\hline Distal/junctional & $196(84.1)$ & $164(97)$ & $32(50)$ & \\
\hline Middle & $37(15.9)$ & $5(3)$ & $32(50)$ & \\
\hline Tumor differentiation & & & & .001 \\
\hline Well/moderate (grade 1/2) & $104(44.6)$ & $65(38.5)$ & $39(60.9)$ & \\
\hline Poor (grade 3) & $111(47.6)$ & $92(54.4)$ & $19(29.7)$ & \\
\hline N/A & $18(7.7)$ & $12(7.1)$ & $6(9.4)$ & \\
\hline Endoscopic tumor length & $5(3,6)$ & $5(3,6)$ & $6(4,8)$ & .002 \\
\hline Pre-CRT EUS & & & & .016 \\
\hline Yes & $195(83.7)$ & $148(87.6)$ & $47(73.4)$ & \\
\hline No & $38(16.3)$ & $21(12.4)$ & $17(26.6)$ & \\
\hline Pre-CRT PET-CT & & & & .219 \\
\hline Yes & $210(90.1)$ & $155(91.7)$ & $55(85.9)$ & \\
\hline No & $23(9.9)$ & $14(8.3)$ & $9(14.1)$ & \\
\hline Post-CRT PET-CT & & & & .004 \\
\hline Yes & $162(69.5)$ & $127(75.1)$ & $35(54.7)$ & \\
\hline No & $71(30.5)$ & $42(24.9)$ & $29(45.3)$ & \\
\hline Pre-CRT SUVm & $12.2(7.3,17.7)$ & $11.5(6.9,18.1)$ & $13.2(8.7,16.9)$ & .278 \\
\hline Post-CRT SUVm & $3.4(1,4.5)$ & $3.6(2.2,4.9)$ & $1(0,3.8)$ & .001 \\
\hline Induction chemotherapy & & & & .46 \\
\hline Yes & $109(46.8)$ & $81(47.9)$ & $28(43.8)$ & \\
\hline No & $116(49.8)$ & $80(47.3)$ & $36(56.2)$ & \\
\hline N/A & $8(3.4)$ & $8(4.7)$ & $0(0)$ & \\
\hline Chemotherapy regimen & & & & $<.001$ \\
\hline Carboplatin/paclitaxel (CROSS) & $73(31.3)$ & $64(37.9)$ & $9(14.1)$ & \\
\hline Other platinum & $139(59.7)$ & $88(52.1)$ & $51(79.7)$ & \\
\hline $5-\mathrm{FU}$ & $14(6)$ & $13(7.7)$ & $1(1.6)$ & \\
\hline Other & $7(3)$ & $4(2.4)$ & $3(4.7)$ & \\
\hline Radiation dose & & & & .527 \\
\hline$<5040$ & $33(14.2)$ & $26(15.4)$ & $7(10.9)$ & \\
\hline$\geq 5040$ & $192(82.4)$ & $137(81.1)$ & $55(85.9)$ & \\
\hline N/A & $8(3.4)$ & $6(3.6)$ & $2(3.1)$ & \\
\hline CRT to surgery (wk) & $8(6.1,10.0)$ & $7.86(6.1,9.9)$ & $8.43(6.6,10.7)$ & .232 \\
\hline Surgical procedure & & & & $<.001$ \\
\hline Ivor Lewis & $200(85.8)$ & $156(92.3)$ & $44(68.8)$ & \\
\hline McKeown 3-hole & $25(10.7)$ & $7(4.1)$ & $18(28.1)$ & \\
\hline Gastrectomy & $1(0.4)$ & $1(0.6)$ & $0(0)$ & \\
\hline Other & $7(3)$ & $5(3)$ & $2(3.1)$ & \\
\hline Tumor bed length $(\mathrm{cm})$ & $2.7(1.8,3.7)$ & $2.7(1.8,3.7)$ & $2.5(1.98,4)$ & .914 \\
\hline Resected lymph nodes & $20(15,27)$ & $20(16,27)$ & $18(11,26.5)$ & .018 \\
\hline Proximal margin $(\mathrm{cm})$ & $5(3,7.5)$ & $5.5(3.2,8.5)$ & $3.5(2.5,5.5)$ & $<.001$ \\
\hline Distal margin $(\mathrm{cm})$ & $5.5(4,7.5)$ & $5.35(4,7)$ & $6.5(4,10)$ & .074 \\
\hline
\end{tabular}


TABLE 1. Continued

\begin{tabular}{lccc}
\hline \multicolumn{1}{c}{ Characteristic } & Overall $(\mathbf{N}=\mathbf{2 3 3})$ & Adenocarcinoma $(\mathbf{N}=\mathbf{1 6 9})$ & SCC $(\mathbf{N}=\mathbf{6 4})$ \\
\hline Residual lesion & & & $\boldsymbol{P}$ value \\
None & $157(67.4)$ & $100(59.2)$ & $57(89.1)$ \\
Barrett's metaplasia & $38(16.3)$ & $35(20.7)$ & $3(4.7)$ \\
Low-grade dysplasia & $19(8.2)$ & $17(10.1)$ & $2(3.1)$ \\
High-grade dysplasia & $19(8.2)$ & $17(10.1)$ & $2(3.1)$ \\
\hline
\end{tabular}

Continuous variables are expressed as median (IQR). Categoric variables are expressed as number (percent). SCC, Squamous cell carcinoma, $N / A$, not available; $C R T$, chemoradiotherapy; EUS, endoscopic ultrasound; PET-CT, positron emission tomography-computed tomography; SUVm, maximum standard uptake value; CROSS, carboplatin + paclitaxel; 5-FU, 5-fluorouracil.

such as Barrett's metaplasia, high-grade, or low-grade dysplasia was recorded.

The standard protocol for recurrence surveillance at our institution is at the discretion of the provider, but usually includes a clinical assessment and a CT chest/abdomen/pelvis with intravenous contrast every 3 to 6 months for the first 2 years after surgery. Yearly scans are done thereafter for 5 years. Routine esophagogastroduodenoscopy is not performed, except in cases of clinical symptoms or suspicious imaging. Some patients who resided far from the institution underwent follow-up with their local physician.

Recurrence within the esophagus or stomach, mediastinal, periesophageal, gastric, celiac, or supraclavicular lymph nodes was classified as loco-regional recurrence (LRR); all other sites were classified as distant recurrence. When both LRR and distant recurrence were identified at the same time, the patient was classified as having distant recurrence.

\section{Statistical Analysis}

Categoric variables were summarized as frequencies and percentages and compared using Fisher exact test, and continuous variables were summarized as medians and interquartile ranges (IQRs) and compared using the Wilcoxon rank-sum test. Time to recurrence was calculated from the date of surgery to the date of recurrence, death, or last follow-up. Death without a recurrence was considered a competing risk event. The cumulative incidence of recurrence (CIR) was estimated using a cumulative incidence function. Site-specific recurrences were also estimated with cumulative incidence functions such that a recurrence at a different site and death without recurrence were considered competing risks. Comparisons between histology groups were assessed using Gray's test.

Risk factors for recurrence were evaluated using Fine-Gray competing risk regression methods. ${ }^{17}$ Clinically relevant variables with a $P$ value less than .2 on univariable analysis were incorporated into the multivariable model. Because of the limited number of events in the EAC subtype, only variables with $P$ value less than .05 were fitted in the final model and in the ESCC subtype, we a priori selected clinically important variables for evaluation in univariable analysis. No multivariable analysis was performed on the ESCC subtype. OS and DFS after surgery were estimated using Kaplan-Meier methods and compared by histology groups using a logrank test. Statistical analyses were performed using SAS 9.4 (SAS Institute, Inc, Cary, NC) and R 3.2.4 (R Development Core Team, Vienna, Austria).

\section{RESULTS}

A total of 233 patients with esophageal cancer (169 with EAC, 64 with ESCC) who achieved pCR after chemoradiotherapy and surgery were included in this study after exclusion criteria were applied. Patient characteristics overall and by histology are shown in Table 1 . Approximately half of patients $(46.8 \%)$ received induction chemotherapy before concurrent chemoradiotherapy, because a PETdirected strategy is currently the standard at our institution as previously described by $\mathrm{Ku}$ and colleagues. ${ }^{18}$ The majority of patients received platinum-based chemotherapy $(91.0 \%)$ and $5040 \mathrm{cGy}$ of radiation $(82.4 \%)$ in the neoadjuvant setting, including 73 patients $(31.3 \%)$ who received the CROSS trial chemotherapy regimen of carboplatin and paclitaxel. Once trimodality therapy was completed, no further adjuvant therapies were delivered and patients were subjected to routine surveillance.

In comparison with EAC, ESCC tumors were longer by endoscopic measurement and better differentiated. Half of ESCC tumors were located in the mid-esophagus versus only $3 \%$ of EAC tumors, and accordingly, McKeown 3hole esophagectomy was performed more often in patients with ESCC than EAC ( $28.1 \%$ vs $4.1 \%)$, with shorter proximal margins (3.5 cm [IQR, 2.5-5.5] vs $5.5 \mathrm{~cm}$ [3.17-8.5], $P=.001)$. A higher number of lymph nodes were retrieved during esophagectomy performed for EAC compared with ESCC (20 [IQR, 16-27] vs 18 [IQR, 11-26.5], $P=.018$ ). OS and DFS at 5 years for patients in this cohort after pCR were 58\% (95\% CI, 55-72) and 53\% (95\% CI, 52$68)$ for EAC, and $61 \%(95 \% \mathrm{CI}, 51-77)$ and $53 \%(95 \%$ CI, 46-71) for ESCC, respectively, and there were no significant difference between histologies (Figures E2 and E3).

\section{Patterns of Recurrence}

A total of 61 patients exhibited recurrence of disease in this cohort, 43 with EAC and 18 with ESCC, whereas 56 patients died without recurrence. Ninety percent patients adhered to our surveillance protocol. Median follow-up among survivors was 42.4 months (range, 0.4-213), and median interval to recurrence was 11.6 months (range, 1.893.6). The CIR did not vary significantly by histology $(P=.85)$ (Figure 1). The 5-year CIR stratified by histology was $28 \%(95 \% \mathrm{CI}, 21-35)$ for EAC and $31 \%$ (95\% CI, 19 43) for ESCC, although the curves begin to plateau at 2 years postesophagectomy. In terms of site of recurrence, 44 patients had recurrence at a distant site and 17 patients had recurrence loco-regionally. Patients with EAC had a higher incidence of distant recurrence in comparison with those with ESCC (Figure 2, A), with the most common sites being the liver and brain (Table 2). Conversely, patients with ESCC demonstrated a higher incidence of LRR $(P=.039)$ (Figure $2, B)$, with mediastinal lymph nodes 


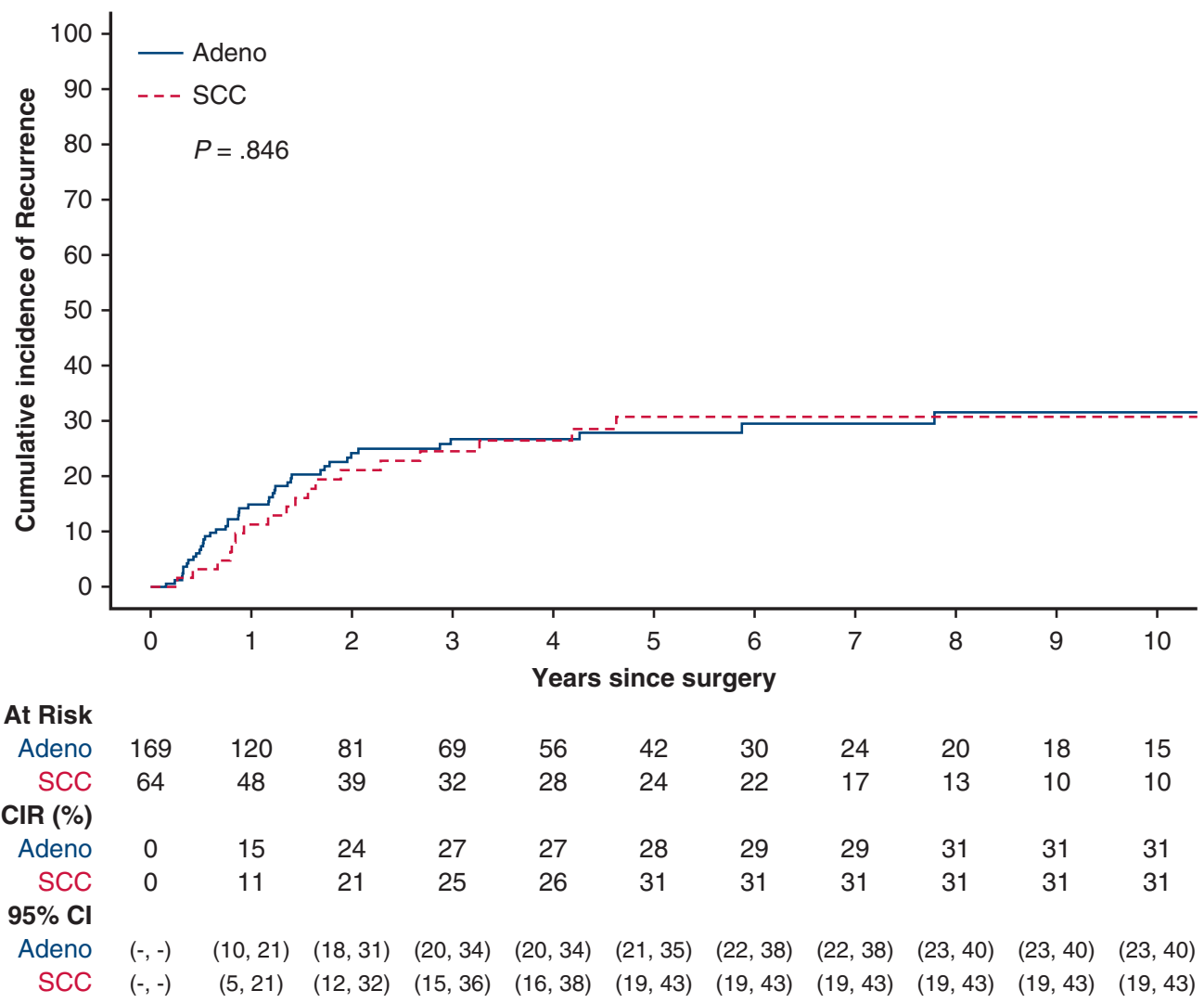

FIGURE 1. CIR stratified by histology. There was no significant difference in the cumulative incidence of disease recurrence between adenocarcinoma and squamous cell carcinoma histologies. SCC, Squamous cell carcinoma; $C I R$, cumulative incidence of recurrence; $C I$, confidence interval.

being the most frequent site (Table 2). Among patients with recurrence, 14 of 61 had recurrence within 6 months postsurgery. Patients with disease recurrence within 6 months postesophagectomy had a significantly worse survival when compared with patients with recurrence after 6 months, $P=.007$ (Figure 3). Recurrent disease was treated palliatively in the majority of cases $(91 \%)$, including chemotherapy in 30 patients $(59 \%)$, a combination of chemotherapy and radiotherapy in 5 patients $(10 \%)$, surgery alone in 3 patients $(6 \%)$, radiotherapy alone in 3 patients $(6 \%)$, and immunotherapy in 1 patient $(2 \%)$. Nine patients $(18 \%)$ were treated with both surgery and radiotherapy, 8 of whom had brain metastases.

\section{Risk Factors for Recurrence}

Results of univariable analysis of risk factors for recurrence in the overall cohort revealed that tumor differentiation grade was the only factor significantly associated with recurrence (HR, 1.79; $P=.035$ ) (Table E1). In multivariable analysis, poor differentiation (ie, grade 3 ) remained the only independent predictor of recurrence (HR, 2.38; $P=.009$ ) (Table 3). Clinical factors were analyzed for association with recurrence for each histologic subtype. In univariable analysis for the EAC subgroup, advanced clinical stage (HR, 1.92; $P=.048)$ and poor tumor differentiation (HR, 2.28; $P=.022$ ) were both associated with recurrence. Multivariable analysis showed that advanced clinical stage remained important (HR, 1.86; $P=.085)$, but poor tumor differentiation once again was the only independent predictor for developing a recurrence (HR, 2.39; $P=.018$ ) (Table 4). In patients with ESCC, no significant risk factors of recurrence were identified on univariable analysis, and multivariable analysis was not performed because of insufficient number of events.

\section{DISCUSSION}

In patients with locally advanced esophageal cancer treated with tri-modality therapy, pCR after esophagectomy portends a positive prognosis in terms of improved survival and a lower rate of recurrence. ${ }^{1,11}$ Despite these outcomes, other studies have reported that $21 \%$ to $39 \%$ of patients with a pCR still have recurrence. ${ }^{8-10}$ In our study, 61 patients with pCR experienced recurrence of disease. To date, few studies have assessed whether clinical and pathologic characteristics may predict recurrence in this patient population. We demonstrate that poor tumor differentiation grade is an independent predictor of recurrence, particularly in the subgroup of patients with 


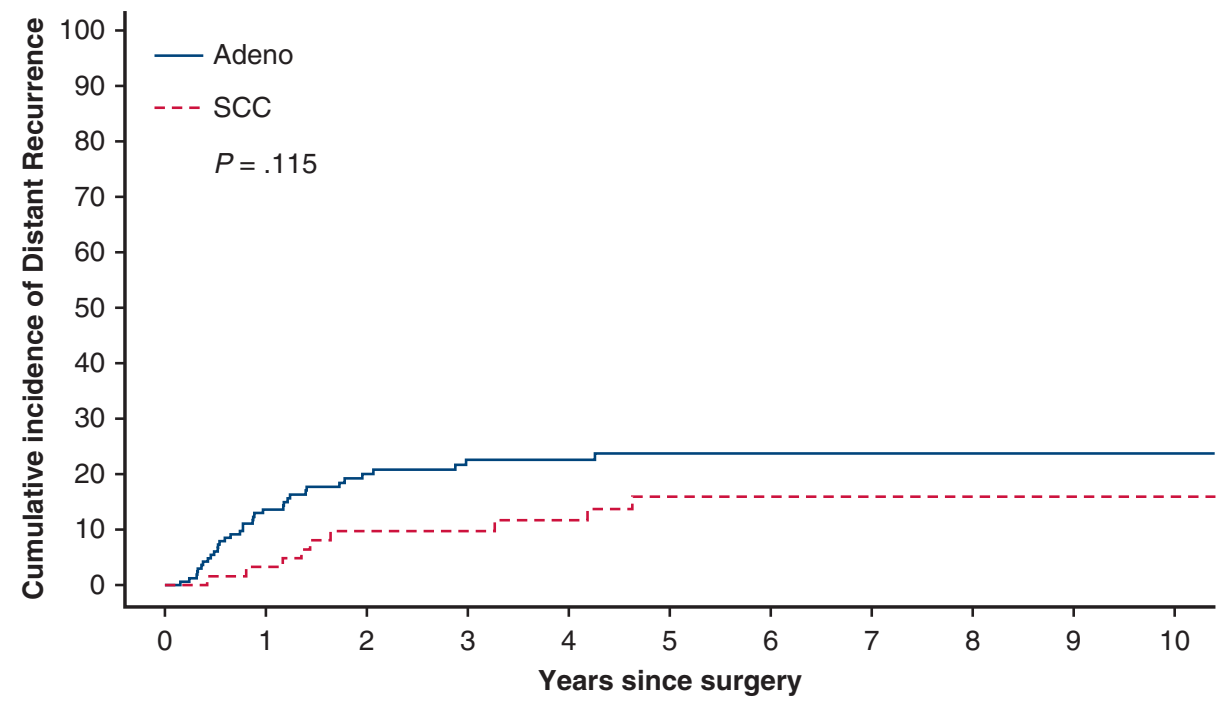

\begin{tabular}{|c|c|c|c|c|c|c|c|c|c|c|c|}
\hline \multicolumn{12}{|l|}{ No. At Risk } \\
\hline Adeno & 169 & 120 & 81 & 69 & 56 & 42 & 30 & 24 & 20 & 18 & 15 \\
\hline SCC & 64 & 48 & 39 & 32 & 28 & 24 & 22 & 17 & 13 & 10 & 10 \\
\hline \multicolumn{12}{|l|}{ CIDR (\%) } \\
\hline Adeno & 0 & 14 & 20 & 23 & 23 & 24 & 24 & 24 & 24 & 24 & 24 \\
\hline SCC & 0 & 3 & 10 & 10 & 12 & 16 & 16 & 16 & 16 & 16 & 16 \\
\hline \multicolumn{12}{|l|}{$95 \% \mathrm{Cl}$} \\
\hline Adeno & $(-,-)$ & $(9,19)$ & $(14,27)$ & $(16,30)$ & $(16,30)$ & $(17,31)$ & $(17,31)$ & $(17,31)$ & $(17,31)$ & $(17,31)$ & $17,31)$ \\
\hline SCC & $(-,-)$ & $(1,10)$ & $(4,19)$ & $(4,19)$ & $(5,21)$ & $(8,27)$ & $(8,27)$ & $(8,27)$ & $(8,27)$ & $(8,27)$ & $(8,27)$ \\
\hline
\end{tabular}

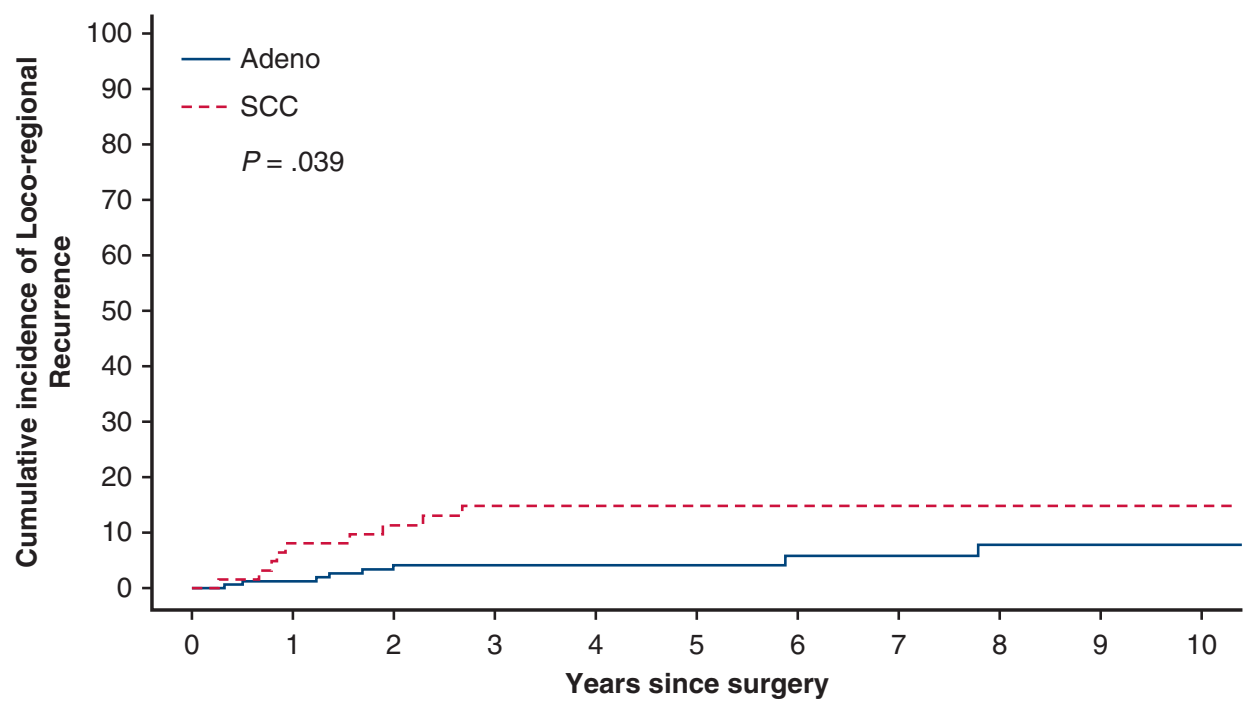

$\begin{array}{rccccccccccc}\text { No. At Risk } & & & & & & & & & & \\ \text { Adeno } & 169 & 120 & 81 & 69 & 56 & 42 & 30 & 24 & 20 & 18 & 15 \\ \text { SCC } & 64 & 48 & 39 & 32 & 28 & 24 & 22 & 17 & 13 & 10 & 10 \\ \text { CIR (\%) } & & & & & & & & & & & \\ \text { Adeno } & 0 & 1 & 4 & 4 & 4 & 4 & 6 & 6 & 8 & 8 & 8 \\ \text { SCC } & 0 & 8 & 11 & 15 & 15 & 15 & 15 & 15 & 15 & 15 & 15 \\ 95 \% \text { Cl } & & & & & & & & & & & \\ \text { Adeno } & (-,-) & (0,4) & (2,8) & (2,8) & (2,8) & (2,8) & (2,11) & (2,11) & (3,15) & (3,15) & (3,15) \\ \text { B SCC } & (-,-) & (3,17) & (5,21) & (7,25) & (7,25) & (7,25) & (7,25) & (7,25) & (7,25) & (7,25) & (7,25)\end{array}$

FIGURE 2. Cumulative incidence of distant recurrence (A) and LRR (B) stratified by histology. A, Patients with adenocarcinoma had a higher incidence of distant recurrences than patients with squamous cell carcinoma, although not statistically significant. B, Conversely, patients with squamous cell carcinoma had a higher incidence of LRR than patients with adenocarcinoma, and this was statistically significant. SCC, Aquamous cell carcinoma; CIDR, cumulative incidence of distant recurrence; $C I$, confidence interval; $C I R$, cumulative incidence of recurrence. 
TABLE 2. Distribution of recurrence sites by histology

\begin{tabular}{lcc}
\hline \multicolumn{1}{c}{ Site of recurrence } & EAC $(\mathbf{N}=\mathbf{4 3})$ & ESCC $(\mathbf{N}=\mathbf{1 8})$ \\
\hline Loco-regional & & \\
Mediastinal LN & $3(7 \%)$ & $6(33 \%)$ \\
Anastomosis/conduit & $1(2.3 \%)$ & $1(5.5 \%)$ \\
Supraclavicular LN & $1(2.3 \%)$ & $2(11 \%)$ \\
Multiple sites & $3(7 \%)$ & 0 \\
Distant & & \\
Brain & $12(28 \%)$ & $1(5.5 \%)$ \\
Liver & $4(9.3 \%)$ & $2(11 \%)$ \\
Bone & $2(4.7 \%)$ & 0 \\
Retroperitoneal LN & $1(2.3 \%)$ & 0 \\
Lung & $2(4.7 \%)$ & $5(27.8 \%)$ \\
Peritoneum & $1(2.3 \%)$ & 0 \\
Multiple organs & $13(30.2 \%)$ & $1(5.5 \%)$ \\
\hline
\end{tabular}

$E A C$, Esophageal adenocarcinoma; ESCC, esophageal squamous cell carcinoma; $L N$, lymph node.

EAC in whom there was adequate statistical power to detect this result. In addition, on univariable analysis, advanced clinical stage was associated with increased risk of recurrence in patients with EAC. These results parallel what others have shown in patients with EAC, including both pCR and non-pCR cohorts. For example, Kim and colleagues ${ }^{19}$ showed that early clinical stage is an independent predictor of recurrence-free survival $(P=.01)$ in patients with a major pathologic response. Moreover, Xi and colleagues ${ }^{6}$ demonstrated that histologic grade (HR, 1.635) and clinical $\mathrm{T}$ stage (HR, 1.717) were both predictors of recurrence in all patients with $\mathrm{EAC}$, whereas histologic grade was not a risk factor for recurrence for ESCC. Our cohort of patients with ESCC with pCR, on the other hand, was insufficiently powered to discern any significant risk factors of recurrence. Because of a shift in treatment paradigm favoring definitive chemoradiotherapy over trimodality therapy in ESCC over time, fewer patients with ESCC were eligible for inclusion in this study, although this trend is reversing once again on the basis of recent data from our institution. ${ }^{20}$ Moreover, our institution's pCR rate for ESCC is also lower than that reported by others, including the CROSS trial, most likely because surgery is almost exclusively performed for high suspicion of residual disease. The findings of our study are further discussed in Video 1.

Unsurprisingly, our data indicate that OS is significantly influenced by the time to recurrence. Although rare, very early recurrences detected within 6 months from CRT-S were associated with significantly worse survival than later recurrences, and this was equivalent between histologies. Most prior studies have shown that there is no significant difference in recurrence pattern, site, timing, DFS, or OS

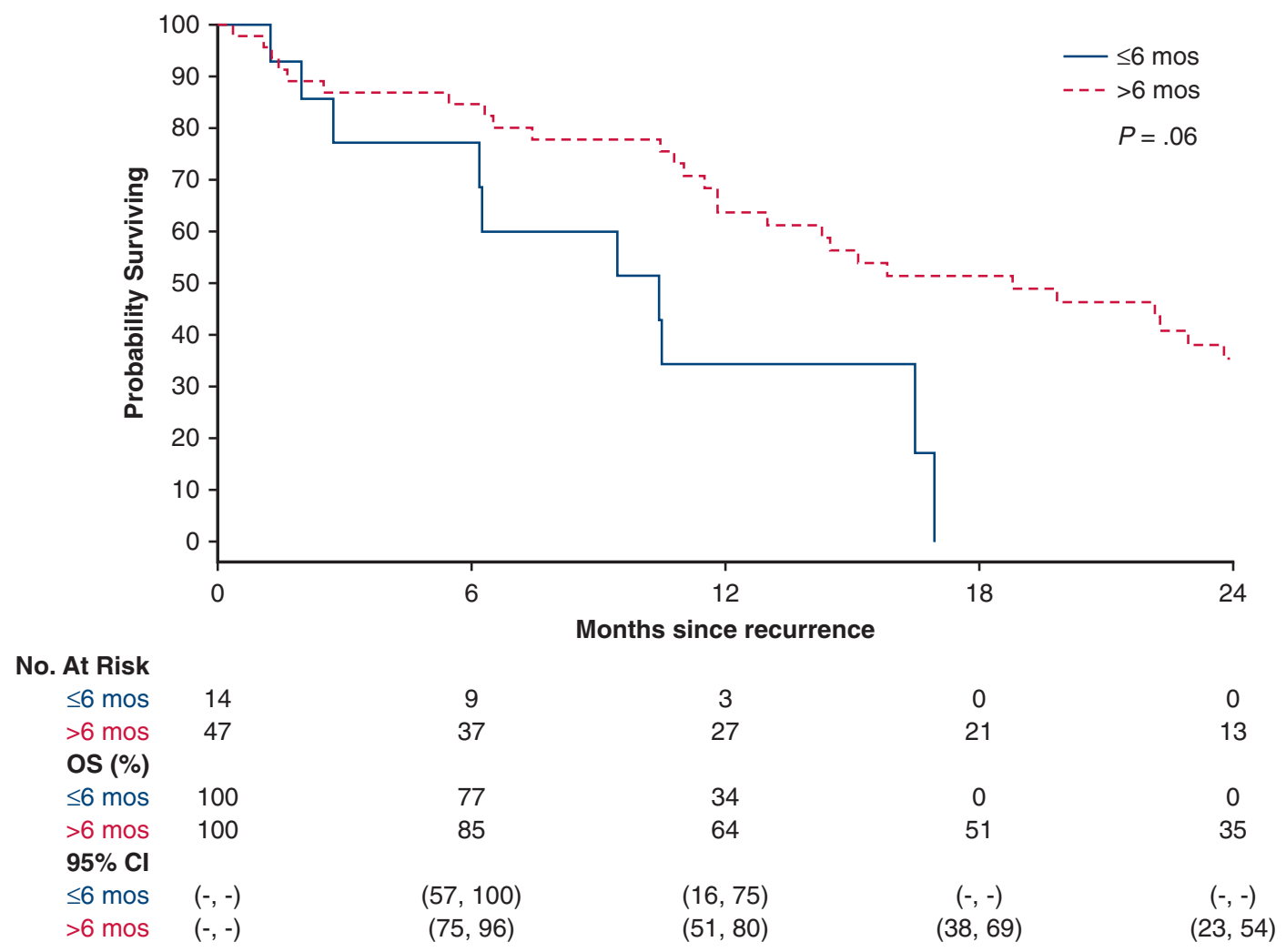

FIGURE 3. OS after recurrence stratified by interval to recurrence. OS was significantly lower in patients with recurrence within 6 months post-treatment in comparison with those who had recurrence beyond this window. OS, Overall survival; $C I$, confidence interval. 
TABLE 3. Multivariable analysis of risk factors for recurrence after pathologic complete response in overall cohort

\begin{tabular}{lcc}
\hline \multicolumn{1}{c}{ Variable } & HR $(\mathbf{9 5} \% \mathbf{C I})$ & $\boldsymbol{P}$ value \\
\hline SUVm pretreatment: yes vs no & $0.98(0.93-1.02)$ & .33 \\
Tumor length $(\mathrm{cm})$ & $0.84(0.65-1.09)$ & .2 \\
Differentiation: poor vs well/moderate & $2.42(1.26-4.64)$ & .008 \\
Radiation dose $\geq 5040$ vs $<5040 \mathrm{cGy}$ & $1.88(0.58-6.11)$ & .29 \\
\hline
\end{tabular}

$H R$, Hazard ratio; $C I$, confidence interval; $S U V m$, maximum standard uptake value.

between EAC and ESCC histologies in patients with pCR, suggesting that both patient groups should continue to undergo similar treatment and surveillance strategies. ${ }^{6,10}$ Only Luc and colleagues ${ }^{14}$ identified EAC histology as a risk factor of recurrence in patients with $\mathrm{pCR}$.

In our study, the median time to recurrence among patients with recurrence was 11.6 months, with no differences in the CIR between EAC and ESCC. Both curves in Figure 1 plateau at 2 years, indicating that nearly all recurrences occur within this time-frame regardless of histology. Xi and colleagues ${ }^{6}$ also found that approximately $80 \%$ of recurrences occur within 2 years in a recent report of the MD Anderson pCR cohort. Thus, we hypothesize that patients in this group may benefit from more frequent surveillance, potentially every 3 to 4 months rather than the current approach of every 6 months. Prospective clinical studies are needed to prove that early detection of recurrence leads to improved survival. Furthermore, most patients with recurrence presented with distant failure $(72 \%)$, which is a consistent trend among both patients with pCR and nonpCR regardless of histology. ${ }^{11,21}$ However, we did observe a significantly higher incidence of LRR in patients with pCR with ESCC in comparison with EAC. This finding differs from other studies that have shown no significant difference in LRR rate between patients with pCR with ESCC versus EAC, and supports a role for extended chest imaging combined with upper endoscopy during surveillance. ${ }^{22}$ Given that the most frequent site of LRR in patients with ESCC was mediastinal lymph nodes, a more complete or extensive mediastinal lymphadenectomy during resection may be justified as well to reduce the incidence of LLR. Conversely, we also observed a higher incidence of distant recurrences in EAC versus ESCC pCR cases, although this did not reach statistical

TABLE 4. Multivariable analysis of risk factors for recurrence after pathologic complete response in esophageal adenocarcinoma

\begin{tabular}{lcc}
\hline \multicolumn{1}{c}{ Variable } & HR $(\mathbf{9 5} \%$ CI $)$ & $\boldsymbol{P}$ value \\
\hline $\begin{array}{l}\text { Tumor grade/differentiation, } \\
\text { poor vs well/moderate }\end{array}$ & $2.39(1.16-4.93)$ & .018 \\
Clinical stage, III vs II & $1.86(0.92-3.76)$ & .085 \\
Radiation dose, $\geq 5040$ vs $<5040$ & $2.14(0.65-7.06)$ & .21 \\
\hline
\end{tabular}

$H R$, Hazard ratio; $C I$, confidence interval.

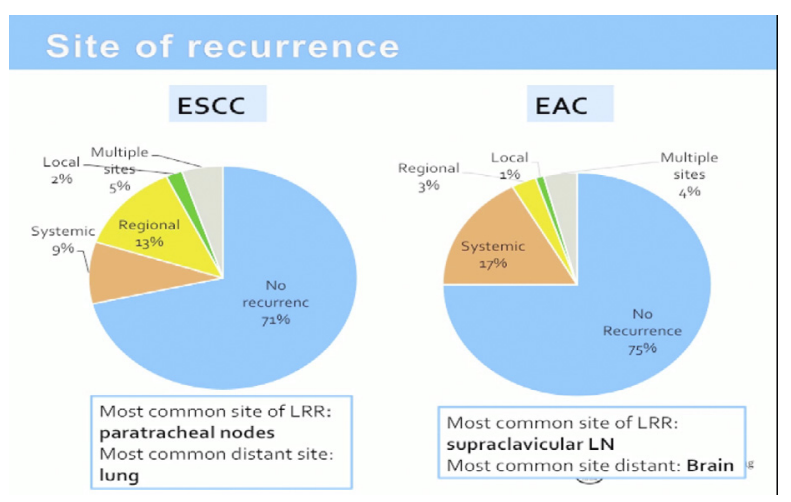

VIDEO 1. Smita Sihag, MD, MPH. Video available at: https://www.jtcvs. org/article/S0022-5223(18)33122-2/fulltext.

significance. Moreover, the most frequent sites of recurrence in patients with EAC pCR were the liver and brain. Fields and colleagues ${ }^{23}$ have reported that one third of recurrences in patients with gastroesophageal cancer with a pCR occur in the brain. Likewise, a recent study of the MD Anderson experience found a $25 \%$ rate of brain recurrences in those with pCR (vs 7\% in those with non-pCR). Because brain scans, either CT or magnetic resonance imaging, are not part of the staging or surveillance routine in patients with esophageal cancer and are only performed when neurologic symptoms arise, this number is likely to be under-reported. However, these findings indicate that axial imaging of the brain should be considered along with CT or PET-CT as part of the routine surveillance strategy in patients with EAC pCR.

\section{Study Limitations}

Our study has several limitations, including its retrospective design and relatively small number of patients, particularly in the ESCC cohort. Moreover, the study period spans over 20 years, during which there was considerable variability in staging modalities, chemotherapy regimens, use of induction chemotherapy, and surgical role and technique. In addition, a small group of patients were not compliant with our standard follow-up protocol. Overall, however, our study is based on one of the largest singlecenter cohort of patients with pCR and includes both EAC and ESCC histologies with a comparison between them.

\section{CONCLUSIONS}

pCR is not necessarily synonymous with cure, because the risk of recurrence remains substantial. Poor tumor differentiation grade represents an independent risk factor for recurrence in patients with pCR, particularly those with $\mathrm{EAC}$, and the majority of these patients have recurrence at distant sites within a 2-year period after treatment. In contrast, patients with pCR with ESCC have a significantly higher rate of LRR. This is the first study to show a 
divergence in patterns of recurrence in $\mathrm{pCR}$ patients by histology, and this may guide treatment and surveillance strategies in the future.

\section{Webcast}

You can watch a Webcast of this AATS meeting presentation by going to: https://aats.blob.core.windows.net/media/18May 01/25ABC \% 202.General \%20Thoracic $\% 20$ SS/S91\%20\%20Part\%202/S91_6_webcast_053057027.mp4.

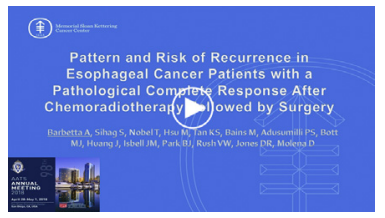

\section{Conflict of Interest Statement}

Authors have nothing to disclose with regard to commercial support.

\section{References}

1. van Hagen P, Hulshof MC, van Lanschot JJ, Steyerberg EW, van Berge Henegouwen MI, Wijnhoven BP, et al. Preoperative chemoradiotherapy for esophageal or junctional cancer. N Engl J Med. 2012;366:2074-84.

2. Liu B, Bo Y, Wang K, Liu Y, Tang X, Zhao Y, et al. Concurrent neoadjuvant chemoradiotherapy could improve survival outcomes for patients with esophageal cancer: a meta-analysis based on random clinical trials. Oncotarget. 2017;8: 20410-7.

3. Gebski V, Burmeister B, Smithers BM, Foo K, Zalcberg J, Simes J. Survival benefits from neoadjuvant chemoradiotherapy or chemotherapy in oesophageal carcinoma: a meta-analysis. Lancet Oncol. 2007;8:226-34.

4. Napier KJ, Scheerer M, Misra S. Esophageal cancer: a review of epidemiology, pathogenesis, staging workup and treatment modalities. World J Gastrointest Oncol. 2014;6:112-20.

5. Cancer Genome Atlas Research Network, Analysis Working Group: Asan University, Agency BCC, Brigham Women's H, Broad I, et al. Integrated genomic characterization of oesophageal carcinoma. Nature. 2017;541:169-75.

6. Xi M, Yang Y, Zhang L, Yang H, Merrell KW, Hallemeier CL, et al. Multi-institutional analysis of recurrence and survival after neoadjuvant chemoradiotherapy of esophageal cancer: impact of histology on recurrence patterns and outcomes. Ann Surg. January 12, 2018 [Epub ahead of print].

7. Blum Murphy M, Xiao L, Patel VR, Maru DM, Correa AM, F GA, et al. Pathological complete response in patients with esophageal cancer after the trimodality approach: the association with baseline variables and survival-The University of Texas MD Anderson cancer center experience. Cancer. 2017;123:4106-13.

8. Meguid RA, Hooker CM, Taylor JT, Kleinberg LR, Cattaneo SM II, Sussman MS, et al. Recurrence after neoadjuvant chemoradiation and surgery for esophageal cancer: does the pattern of recurrence differ for patients with complete response and those with partial or no response? J Thorac Cardiovasc Surg. 2009; 138:1309-17.

9. Jipping KM, Hulshoff JB, van Amerongen EA, Bright TI, Watson DI Plukker JTM. Influence of tumor response and treatment schedule on the distribution of tumor recurrence in esophageal cancer patients treated with neoadjuvant chemoradiotherapy. J Surg Oncol. 2017;116:1096-102.

10. Vallbohmer D, Holscher AH, DeMeester S, DeMeester T, Salo J, Peters J, et al. A multicenter study of survival after neoadjuvant radiotherapy/chemotherapy and esophagectomy for ypT0N0M0R0 esophageal cancer. Ann Surg. 2010;252: 744-9.

11. van Hagen P, Wijnhoven BP, Nafteux P, Moons J, Haustermans K, De Hertogh G, et al. Recurrence pattern in patients with a pathologically complete response after neoadjuvant chemoradiotherapy and surgery for oesophageal cancer. Br J Surg. 2013;100:267-73.
12. Rizk NP, Venkatraman E, Bains MS, Park B, Flores R, Tang L, et al. American joint committee on cancer staging system does not accurately predict survival in patients receiving multimodality therapy for esophageal adenocarcinoma. $J$ Clin Oncol. 2007;25:507-12.

13. Xi M, Hallemeier CL, Merrell KW, Liao Z, Murphy MAB, Ho L, et al. Recurrence risk stratification after preoperative chemoradiation of esophageal adenocarcinoma. Ann Surg. 2018;268:289-95.

14. Luc G, Gronnier C, Lebreton G, Brigand C, Mabrut JY, Bail JP, et al. Predictive factors of recurrence in patients with pathological complete response after esophagectomy following neoadjuvant chemoradiotherapy for esophageal cancer: a multicenter study. Ann Surg Oncol. 2015;22(Suppl 3):S1357-64.

15. Chao YK, Chan SC, Liu YH, Chen HW, Wan YL, Chang HK, et al. Pretreatment T3-4 stage is an adverse prognostic factor in patients with esophageal squamous cell carcinoma who achieve pathological complete response following preoperative chemoradiotherapy. Ann Surg. 2009;249:392-6.

16. Rizk NP, Seshan VE, Bains MS, Ilson DH, Minsky BD, Tang L, et al. Prognostic factors after combined modality treatment of squamous cell carcinoma of the esophagus. J Thorac Oncol. 2007;2:1117-23.

17. Fine JPGR. A proportional haxards model for the subdistribution of competing risk. J Am Stat Assoc. 1999;94:496-509.

18. Ku GY, Kriplani A, Janjigian YY, Kelsen DP, Rusch VW, Bains M, et al. Change in chemotherapy during concurrent radiation followed by surgery after a suboptimal positron emission tomography response to induction chemotherapy improves outcomes for locally advanced esophageal adenocarcinoma. Cancer. 2016;122:2083-90.

19. Kim MK, Cho KJ, Park SI, Kim YH, Kim JH, Song HY, et al. Initial stage affects survival even after complete pathologic remission is achieved in locally advanced esophageal cancer: analysis of 70 patients with pathologic major response after preoperative chemoradiotherapy. Int J Radiat Oncol Biol Phys. 2009;75:115-21.

20. Barbetta A, Hsu M, Tan KS, Stefanova D, Herman K, Adusumilli PS, et al. Definitive chemoradiotherapy versus neoadjuvant chemoradiotherapy followed by surgery for stage II to III esophageal squamous cell carcinoma. J Thorac Cardiovasc Surg. 2018;155:2710-21.e3.

21. Koshy M, Greenwald BD, Hausner P, Krasna MJ, Horiba N, Battafarano RJ, et al Outcomes after trimodality therapy for esophageal cancer: the impact of histology on failure patterns. Am J Clin Oncol. 2011;34:259-64.

22. Oppedijk V, van der Gaast A, van Lanschot JJ, van Hagen P, van Os R, van Rij CM, et al. Patterns of recurrence after surgery alone versus preoperative chemoradiotherapy and surgery in the CROSS trials. J Clin Oncol. 2014;32:385-91.

23. Fields RC, Strong VE, Gonen M, Goodman KA, Rizk NP, Kelsen DP, et al Recurrence and survival after pathologic complete response to preoperative therapy followed by surgery for gastric or gastrooesophageal adenocarcinoma. $\mathrm{Br} J$ Cancer. 2011;104:1840-7.

Key Words: esophageal cancer, neoadjuvant chemoradiotherapy plus surgery, recurrence, pathologic complete response, survival

\section{Discussion}

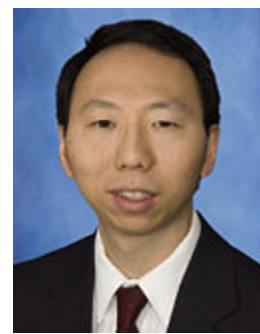

Dr Jules Lin (Ann Arbor, Mich). This patient population is challenging to talk to in clinic and tell them, on the one hand, you can celebrate, you have a complete response, your survival should be better, but, on the other hand, there is still a $20 \%$ to $30 \%$ chance of the cancer recurring. You provided some data that help to clarify which patients are more likely to have recurrence, where they are going to have recurrence, and which patients should be watched, and that's an area that's still unclear and controversial. 
One of the things you read in previous articles is that patients who have more advanced disease have had more recurrences and poorer survival, but in your article and presentation, recurrences were not associated with lymph node status or $\mathrm{T}$ stage, and in the ultimate model they were not associated with advanced stage. Why could that be? Could it be because of the length of the study? I know you said that was one of the limitations. It looked like up to $14 \%$ of the patients at least in the esophageal squamous group did not have PET scans. Did you consider excluding those patients, and if you excluded those patients and looked at just those who had a complete pretreatment staging, were you more likely to find that advanced stage was associated with recurrence?

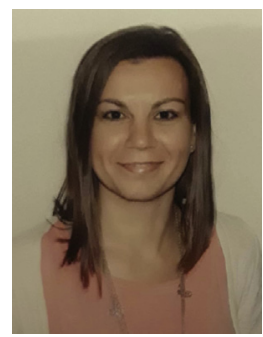

Dr Arianna Barbetta (New York, NY). A few patients did not have a PET/CT done before treatment, and usually PET/CT increases the accuracy of metastatic staging approximately $5 \%$ to $10 \%$. So it is unlikely that excluding those patients would have had any impact on the observed results. The rate of response to chemotherapy most likely is not related to the amount of tumor or extension of disease, but probably to the patient and tumor characteristics, especially for those with pCR in whom chemotherapy eradicates the tumor completely.

Dr Lin. Then for the patients who had a complete response, you were essentially finding the false-negatives, so that you are finding those with recurrence are those whom you did not identify, patients who had residual disease, and many of those are patients who had distant disease. For those with ESCC, you found higher LRR. Those patients also had less lymph nodes removed. Do you think that could contribute to that finding?

Dr Barbetta. I think so. It could be that the number of lymph nodes removed was inadequate and microscopic disease might have been left behind.

Dr Lin. In many of the patients, especially those with adenocarcinoma, the recurrence was distant and that's not unexpected, and so finding more effective chemotherapy would be important. I think one of the things in this series is that approximately $50 \%$ of your patients had a unique regimen of neoadjuvant chemoradiation in that they got induction chemotherapy, then they had a PET scan to look at response, and the nonresponders had a change in their chemotherapy; in a previous article from Sloan-Kettering, there was a good response in those patients. Would you expect those patients to have a decrease in recurrence in this study, which it didn't seem like there was an with it?

Dr Barbetta. Patients in whom the chemotherapy regimen was changed?

Dr Lin. Yes.

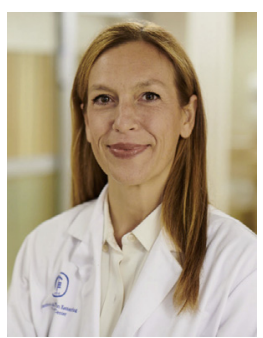

Dr Daniela Molena (New York, NY). Arianna just finished medical school, so I will try to help her out. We don't have enough patients to do a subanalysis on those patients who had induction chemotherapy; however, in a previous article published by our institution, patients who had induction chemotherapy before chemoradiation had a slight advantage in terms of DFS, but there was no difference in OS in the entire group of patients with adenocarcinoma.

Dr Lin. She did great. Congratulations on your work.

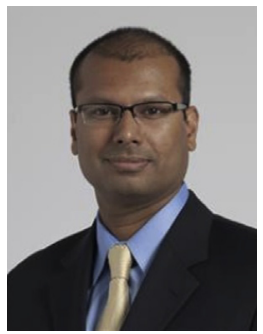

Dr Siva Raja (Cleveland, Ohio). Thank you for taking a stab at a subject that there is always a topic on trying to figure out a way they recur. It has been well documented that brain metastases happen more frequently in patients who have had trimodality therapy than people who present with brain metastases, but the people don't routinely get followed with brain magnetic resonance imaging (MRI). What was the frequency of your brain metastases even though that was one of the higher areas of recurrence?

Dr Barbetta. We had 13 patients with brain metastases in the adenocarcinoma group and 1 patient in the squamous cell subgroup.

Dr Raja. How far out were they before they developed brain metastases?

Dr Barbetta. The majority occurred within 1 year after surgery. Because we do not routinely screen for brain metastasis, most of these patients were symptomatic at diagnosis.

Dr Raja. Some $54 \%$ of your patients in the adenocarcinoma group had poor differentiation. How many of them were signet ring cancers, because most people believe that they are 2 different animals, you know, like poor differentiation is one thing, but once you get to signet ring, the pathology arguably is worse. Do you have any information on that?

Dr Barbetta. I don't recall the exact number, but we looked at the specific variable "signet ring cell," and there was no association with recurrence.

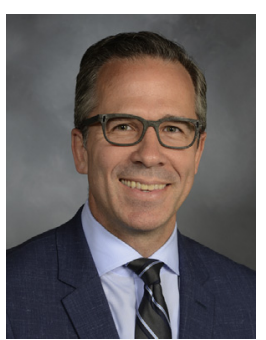

Dr Brendon Stiles (New York, NY). One important thing is the value of the 3 -field dissection in squamous cell cancers. I think we sometimes get lulled into a false sense of security with radiation, which often doesn't cover the upper neck, and we also get lulled with minimally invasive esophagectomy where the third field is maybe tougher. It looks like approximately $11 \%$ of the patients had a 3-hole 
esophagectomy, but it strikes me as a high LRR for the squamous cells cancers. Did they really have complete pathologic responses or did they just not get dissected high enough? I know it's a small number, but was there a difference between the 3 holes and the Ivor-Lewis resections with regard to recurrence?

Dr Barbetta. I didn't show these data, but $50 \%$ of patients with squamous cell cancer had a midesophageal tumor and they did undergo more frequently to 3-hole esophagectomy. However, we don't know if a more extensive lymphadenectomy in these patients would have prevented LRR.

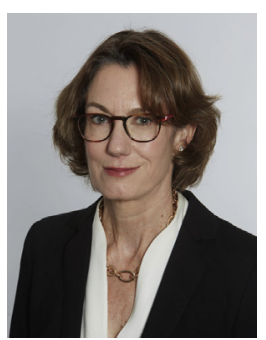

Dr Virginia Litle (Boston, Mass). So are you now surveying for brain lesions with MRI or head CT scans with your routine follow-up body $\mathrm{CT}$ scans routinely because of your results?

Dr Molena. We are not doing it routinely, but I think our data suggest there might be a role for it. The overall group of patients with chemoradiation had a higher incidence of brain metastases, but particularly patients with adenocarcinoma, and especially patients with PCR. So I think that it would be a good standard to include brain MRI or CT scan as standard follow-up for these patients in the future. What remains unclear is the impact of early detection and possibly treatment of brain metastasis on the overall outcome.
Dr Litle. Do you know yet at about what interval you would start the surveillance imaging?

Dr Molena. These patients, for the most part, had recurrence within the first 6 to 12 months, and we did not observe any recurrence after 2 years. There were few recurrences within the first 5 months, although we only have data on symptomatic patients. I think we should follow the patients closely with brain imaging between 6 months and 2 years, probably every 6 months.

Dr Litle. I am not sure I agree with that, because if these patients all get symptoms and whatever therapy you offer them is never going to be curative, it may be palliative. Unless it prolongs survival, why find it this month versus next month?

Dr Molena. Well, we actually looked just at the patients with isolated brain metastases but we haven't published these data yet. Patients with pCR and isolated brain metastases were treated far better than patients without pCR. Perhaps if they are diagnosed earlier, when asymptomatic, they might have a better outcome. This of course remains to be proven.

Dr Litle. I think that's the important thing, 1 versus multiple metastases. So if a patient has 1 metastasis and it's resectable, we know those people do well based on lung cancer experience.

Dr Molena. Right. It seems like this might be true for esophageal cancer as well, but we haven't looked carefully or published these data yet. 


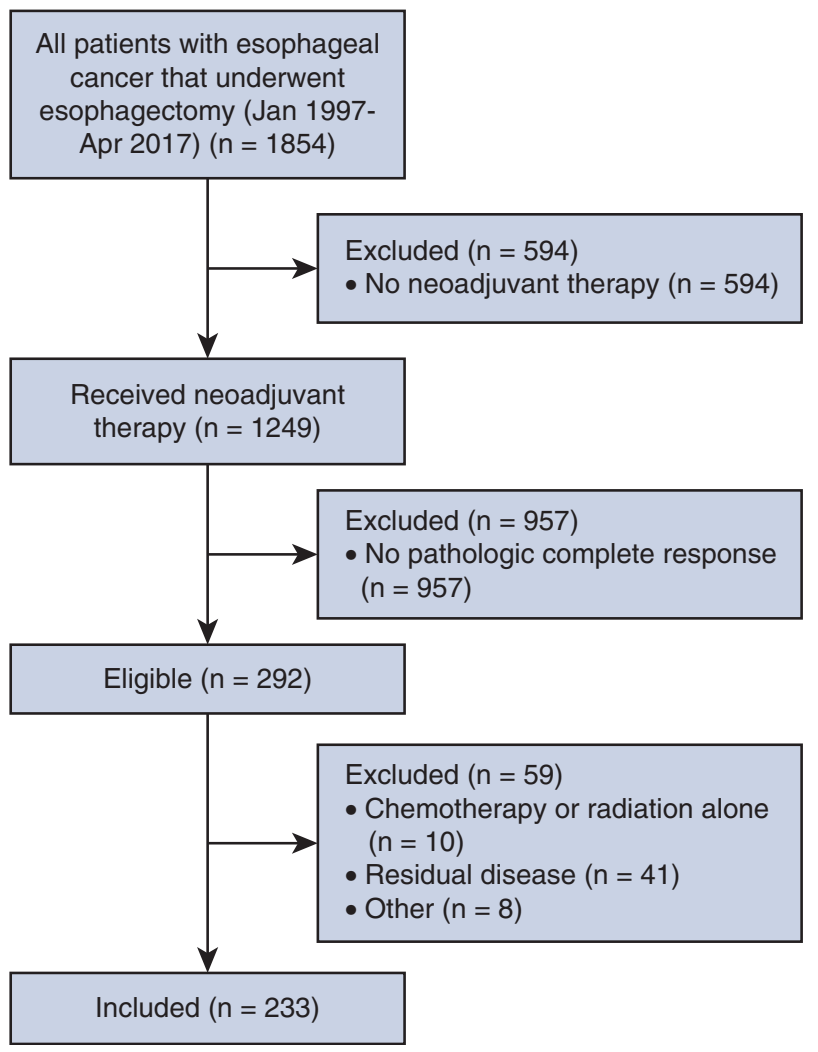

FIGURE E1. Study cohort, with excluded patients. 


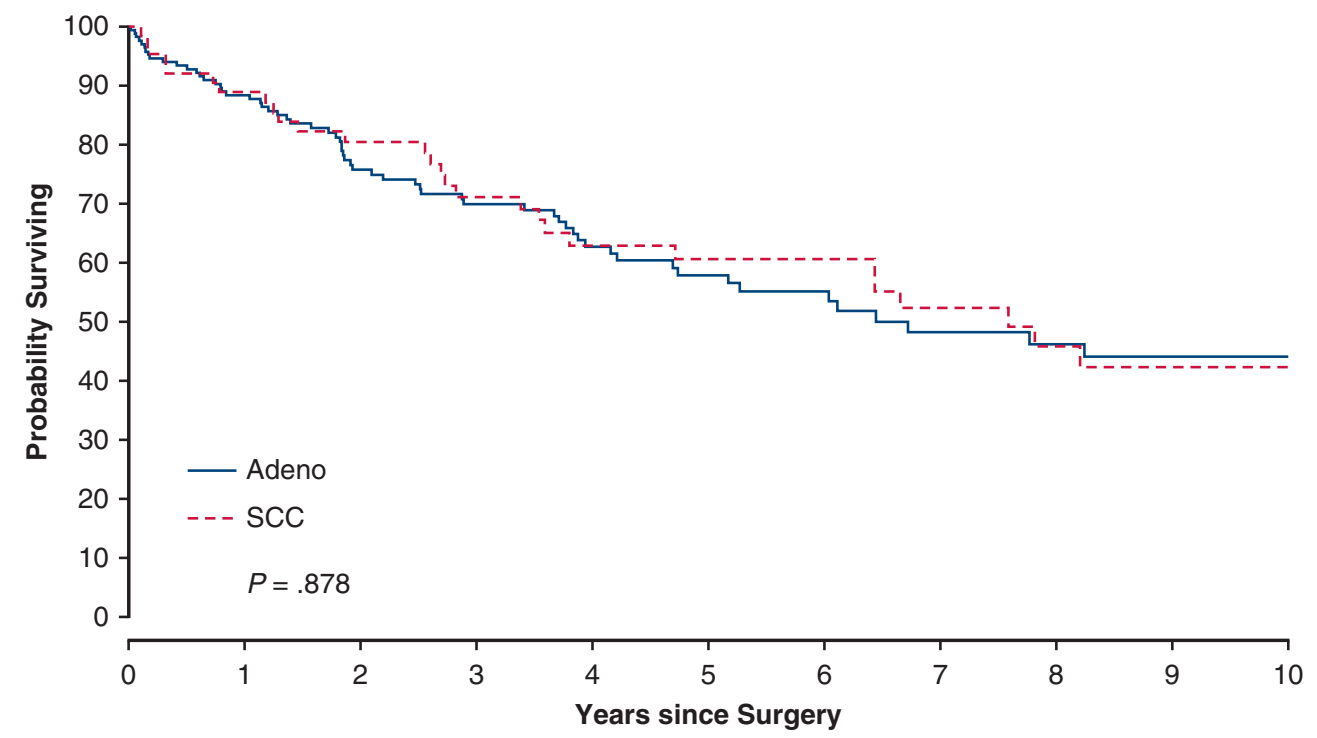

No. At Risk

$\begin{array}{rccccccccccc}\text { Adeno } & 169 & 136 & 94 & 79 & 57 & 44 & 33 & 26 & 23 & 19 & 16 \\ \text { SCC } & 64 & 54 & 46 & 37 & 30 & 27 & 25 & 18 & 13 & 10 & 10 \\ \text { OS (\%) } & & & & & & & & & & & \\ \text { Adeno } & 100 & 88 & 76 & 70 & 63 & 58 & 55 & 48 & 46 & 44 & 44 \\ \text { SCC } & 100 & 89 & 81 & 71 & 63 & 61 & 61 & 52 & 46 & 42 & 42\end{array}$

95\% C

Adeno

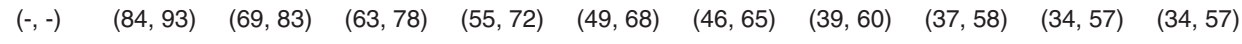

SCC

$(-,-)$

$(81,97) \quad(71,91) \quad(60,84)$

$(51,77) \quad(49,75)$

$(49,75)$

FIGURE E2. OS by histology. OS in patients with adenocarcinoma and SCC does not differ significantly and approaches $60 \%$ at 5 years. SCC, Squamous cell carcinoma; $O S$, overall survival; $C I$, confidence interval. 


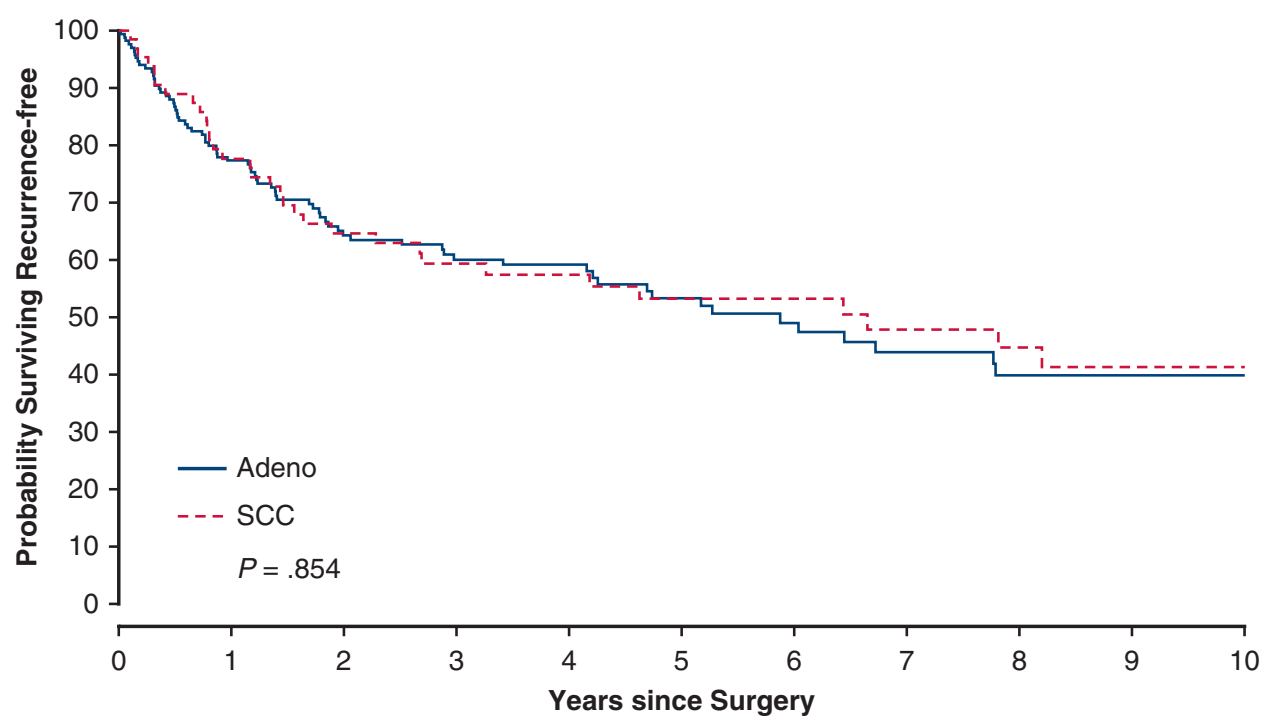

No. At Risk

$\begin{array}{rccccccccccc}\text { Adeno } & 169 & 120 & 81 & 69 & 56 & 42 & 30 & 24 & 20 & 18 & 15 \\ \text { SCC } & 64 & 48 & 39 & 32 & 28 & 24 & 22 & 17 & 13 & 10 & 10 \\ \text { DFS (\%) } & & & & & & & & & & & \\ \text { Adeno } & 100 & 77 & 64 & 60 & 59 & 53 & 49 & 44 & 40 & 40 & 40 \\ \text { SCC } & 100 & 78 & 65 & 59 & 57 & 53 & 53 & 48 & 45 & 41 & 41 \\ 95 \% \text { Cl } & & & & & & & & & & & \\ \text { Adeno } & (-,-) & (71,84) & (57,72) & (53,69) & (52,68) & (45,63) & (41,59) & (35,55) & (31,52) & (31,52) & (31,52) \\ \text { SCC } & (-,-) & (68,89) & (54,78) & (48,73) & (46,71) & (42,68) & (42,68) & (36,64) & (33,61) & (29,59) & (29,59)\end{array}$

FIGURE E3. DFS by histology. DFS in patients with adenocarcinoma and SCC does not differ significantly and approaches $53 \%$ at 5 years. SCC, Squamous cell carcinoma; $C I$, confidence interval; $D F S$, disease-free survival. 
TABLE E1. Univariable analysis of risk factors for recurrence after pathologic complete response

\begin{tabular}{|c|c|c|c|c|c|c|c|c|c|c|c|c|}
\hline \multirow[b]{2}{*}{ Characteristics } & \multicolumn{4}{|c|}{ Overall $(\mathbf{N}=\mathbf{2 3 3})$} & \multicolumn{4}{|c|}{ EAC $(N=169)$} & \multicolumn{4}{|c|}{$\operatorname{ESCC}(N=64) *$} \\
\hline & $\begin{array}{l}\mathrm{N} \text { at } \\
\text { risk }\end{array}$ & $\begin{array}{c}\mathrm{N} \\
\text { recurred }\end{array}$ & $\begin{array}{c}\text { HR } \\
(95 \% \mathrm{CI})\end{array}$ & $P$ & $\begin{array}{l}\mathrm{N} \text { at } \\
\text { risk }\end{array}$ & $\begin{array}{c}\mathrm{N} \\
\text { recurred }\end{array}$ & $\begin{array}{c}\text { HR } \\
(95 \% \mathrm{CI})\end{array}$ & $P$ & $\begin{array}{l}\mathrm{N} \text { at } \\
\text { risk }\end{array}$ & $\begin{array}{c}\mathrm{N} \\
\text { recurred }\end{array}$ & $\begin{array}{c}\text { HR } \\
(95 \% \mathrm{CI})\end{array}$ & $P$ \\
\hline Age & 233 & 61 & $1.01(0.98-1.03)$ & .59 & 169 & 43 & $1.00(0.98-1.03)$ & .77 & & & & \\
\hline Pre-CRT SUVm & 197 & 51 & $0.97(0.94-1.01)$ & .18 & 147 & 37 & $0.99(0.95-1.02)$ & .47 & & & & \\
\hline Post-CRT SUVm & 157 & 40 & $0.94(0.82-1.07)$ & .33 & 122 & 28 & $0.95(0.81-1.11)$ & .49 & & & & \\
\hline Tumor length $(\mathrm{cm})$ & 210 & 54 & $0.88(0.73-1.05)$ & .16 & 150 & 37 & $0.93(0.75-1.14)$ & .48 & & & & \\
\hline Endoscopic Length (cm) & 193 & 54 & $1.00(0.91-1.10)$ & .98 & 140 & 38 & $1.07(0.94-1.21)$ & .33 & 53 & 16 & $0.91(0.77-1.08)$ & .29 \\
\hline Resected lymph nodes & 233 & 61 & $1.00(0.97-1.02)$ & .91 & 169 & 43 & $0.99(0.96-1.02)$ & .57 & & & & \\
\hline Proximal margin $(\mathrm{cm})$ & 181 & 45 & $0.98(0.89-1.08)$ & .7 & 132 & 33 & $1.00(0.90-1.11)$ & .98 & & & & \\
\hline Distal margin $(\mathrm{cm})$ & 161 & 39 & $1.03(0.94-1.13)$ & .55 & 124 & 31 & $1.02(0.91-1.16)$ & .71 & & & & \\
\hline CRT to surgery (wk) & 224 & 58 & $0.98(0.93-1.04)$ & .6 & 163 & 40 & $1.00(0.95-1.06)$ & .99 & & & & \\
\hline Sex & & & & .87 & & & & .28 & & & & \\
\hline Female & 49 & 13 & 1 & & 20 & 3 & 1 & & & & & \\
\hline Male & 184 & 48 & $1.05(0.57-1.95)$ & & 149 & 40 & $1.92(0.58-6.31)$ & & & & & \\
\hline Race & & & & .33 & & & & .51 & & & & \\
\hline Others & 26 & 5 & 1 & & 12 & 2 & 1 & & & & & \\
\hline White & 207 & 56 & $1.55(0.64-3.75)$ & & 157 & 41 & $1.59(0.40-6.42)$ & & & & & \\
\hline Pulmonary comorbidity & & & & .37 & & & & .077 & & & & \\
\hline None & 207 & 56 & 1 & & 151 & 42 & 1 & & & & & \\
\hline Yes & 26 & 5 & $0.67(0.27-1.62)$ & & 18 & 1 & $0.17(0.02-1.21)$ & & & & & \\
\hline Cardiac comorbidity & & & & .35 & & & & .38 & & & & \\
\hline None & 117 & 27 & 1 & & 86 & 19 & 1 & & & & & \\
\hline Yes & 116 & 34 & $1.27(0.77-2.10)$ & & 83 & 24 & $1.31(0.72-2.37)$ & & & & & \\
\hline Diabetes & & & & .27 & & & & .15 & & & & \\
\hline None & 209 & 53 & 1 & & 147 & 35 & 1 & & & & & \\
\hline Yes & 24 & 8 & $1.50(0.73-3.07)$ & & 22 & 8 & $1.72(0.83-3.57)$ & & & & & \\
\hline Tumor location & & & & .48 & & & & - & & & & .097 \\
\hline Distal/GE Junction & 196 & 49 & 1 & & 164 & 43 & 1 & & 32 & 6 & 1 & \\
\hline Middle & 37 & 12 & $1.24(0.68-2.29)$ & & 5 & 0 & Not estimable & & 32 & 12 & $2.26(0.86-5.92)$ & \\
\hline Histology & & & & .89 & & & & & & & & \\
\hline Inv adenocarcinoma & 169 & 43 & 1 & & & & & & & & & \\
\hline SCC & 64 & 18 & $0.96(0.56-1.65)$ & & & & & & & & & \\
\hline Signet ring cells & & & & .77 & & & & .53 & & & & \\
\hline No & 137 & 34 & 1 & & 137 & 34 & 1 & & & & & \\
\hline Yes & 29 & 9 & $1.29(0.62-2.70)$ & & 29 & 9 & $1.26(0.61-2.60)$ & & & & & \\
\hline $\mathrm{SCC}$ & 64 & 18 & $0.99(0.56-1.73)$ & & - & - & - & & & & & \\
\hline Tumor differentiation & & & & .035 & & & & .022 & & & & .84 \\
\hline Well/moderate & 104 & 20 & 1 & & 65 & 10 & 1 & & 39 & 10 & 1 & \\
\hline Poor & 111 & 36 & $1.79(1.04-3.07)$ & & 92 & 30 & $2.28(1.13-4.6)$ & & 19 & 6 & $1.11(0.42-2.92)$ & \\
\hline Clinical T-stage & & & & .74 & & & & .32 & & & & \\
\hline $\mathrm{T} 1 / \mathrm{T} 2$ & 37 & 8 & 1 & & 28 & 4 & 1 & & & & & \\
\hline $\mathrm{T} 3$ & 185 & 50 & $1.31(0.63-2.75)$ & & 132 & 37 & $2.20(0.79-6.13)$ & & & & & \\
\hline $\mathrm{T} 4$ & 11 & 3 & $1.49(0.38-5.95)$ & & 9 & 2 & $1.77(0.31-9.99)$ & & & & & \\
\hline Clinical N-stage & & & & .42 & & & & .22 & & & & \\
\hline No & 66 & 18 & 1 & & 51 & 11 & 1 & & & & & \\
\hline N1 & 144 & 36 & $0.91(0.53-1.59)$ & & 101 & 26 & $1.25(0.63-2.49)$ & & & & & \\
\hline $\mathrm{N} 2+$ & 23 & 7 & $1.64(0.66-4.09)$ & & 17 & 6 & $2.43(0.89-6.65)$ & & & & & \\
\hline Clinical stage & & & & .42 & & & & .048 & & & & .081 \\
\hline II & 87 & 21 & 1 & & 66 & 12 & 1 & & 21 & 9 & 1 & \\
\hline III & 146 & 40 & $1.24(0.74-2.08)$ & & 103 & 31 & $1.92(1.01-3.68)$ & & 43 & 9 & $0.44(0.18-1.1)$ & \\
\hline
\end{tabular}


TABLE E1. Continued

\begin{tabular}{|c|c|c|c|c|c|c|c|c|c|c|c|c|}
\hline \multirow[b]{2}{*}{ Characteristics } & \multicolumn{4}{|c|}{ Overall $(\mathbf{N}=\mathbf{2 3 3})$} & \multicolumn{4}{|c|}{$\operatorname{EAC}(N=169)$} & \multicolumn{4}{|c|}{$\operatorname{ESCC}(N=64) *$} \\
\hline & $\begin{array}{l}\mathrm{N} \text { at } \\
\text { risk }\end{array}$ & $\begin{array}{c}\mathrm{N} \\
\text { recurred }\end{array}$ & $\begin{array}{c}\text { HR } \\
(95 \% \mathrm{CI})\end{array}$ & $P$ & $\begin{array}{l}\mathrm{N} \text { at } \\
\text { risk }\end{array}$ & $\begin{array}{c}\mathrm{N} \\
\text { recurred }\end{array}$ & $\begin{array}{c}\text { HR } \\
(95 \% \mathrm{CI})\end{array}$ & $P$ & $\begin{array}{l}\mathrm{N} \text { at } \\
\text { risk }\end{array}$ & $\begin{array}{c}\mathrm{N} \\
\text { recurred }\end{array}$ & $\begin{array}{c}\text { HR } \\
(95 \% \mathrm{CI})\end{array}$ & $P$ \\
\hline Induction chemotherapy & & & & .36 & & & & .47 & & & & \\
\hline No & 116 & 28 & 1 & & 80 & 19 & 1 & & & & & \\
\hline Yes & 109 & 31 & $1.27(0.76-2.10)$ & & 81 & 22 & $1.25(0.68-2.29)$ & & & & & \\
\hline Chemotherapy regimen & & & & .20 & & & & .55 & & & & - \\
\hline Other Platinum & 139 & 39 & 1 & & 88 & 26 & 1 & & 51 & 13 & 1 & \\
\hline $\begin{array}{l}\text { Carboplatin/Paclitaxel } \\
\text { (CROSS) }\end{array}$ & 73 & 16 & $1.03(0.57-1.85)$ & & 64 & 13 & $0.87(0.45-1.71)$ & & 9 & 3 & $1.71(0.46-6.43)$ & \\
\hline 5-FU & 14 & 2 & $0.62(0.14-2.67)$ & & 13 & 2 & $0.64(0.15-2.77)$ & & 1 & 0 & Not estimable & \\
\hline Other & 7 & 4 & $2.28(1.01-5.15)$ & & 4 & 2 & $1.9(0.62-5.77)$ & & 3 & 2 & $2.89(0.83-10.04)$ & \\
\hline Radiation dose & & & & .19 & & & & .13 & & & & \\
\hline$<5040$ & 33 & 5 & 1 & & 26 & 3 & 1 & & & & & \\
\hline$\geq 5040$ & 192 & 55 & $1.87(0.74-4.73)$ & & 137 & 39 & $2.54(0.77-8.38)$ & & & & & \\
\hline Residual lesion & & & & .39 & & & & .45 & & & & .59 \\
\hline In situ & 19 & 7 & 1 & & 17 & 6 & 1 & & 2 & 1 & 1 & \\
\hline No residual cancer & 214 & 54 & $0.72(0.34-1.53)$ & & 152 & 37 & $0.72(0.31-1.68)$ & & 62 & 17 & $0.65(0.14-3.1)$ & \\
\hline Any complications & & & & .745 & & & & .462 & & & & \\
\hline No & 121 & 31 & 1 & & 86 & 20 & 1 & & & & & \\
\hline Yes & 112 & 30 & $1.09(0.66-1.79)$ & & 83 & 23 & $1.25(0.69-2.26)$ & & & & & \\
\hline Pulmonary complications & & & & .53 & & & & .99 & & & & \\
\hline No & 186 & 51 & 1 & & 136 & 35 & 1 & & & & & \\
\hline Yes & 47 & 10 & $0.80(0.40-1.60)$ & & 33 & 8 & $1.00(0.46-2.16)$ & & & & & \\
\hline Cardiac complications & & & & .44 & & & & .94 & & & & \\
\hline No & 179 & 49 & 1 & & 129 & 33 & 1 & & & & & \\
\hline Yes & 54 & 12 & $0.78(0.42-1.46)$ & & 40 & 10 & $0.97(0.48-1.97)$ & & & & & \\
\hline Anastomotic leak & & & & .26 & & & & .27 & & & & \\
\hline No & 202 & 50 & 1 & & 147 & 35 & 1 & & & & & \\
\hline Yes & 31 & 11 & $1.44(0.76-2.76)$ & & 22 & 8 & $1.52(0.72-3.21)$ & & & & & \\
\hline Surgery era & & & & .90 & & & & .97 & & & & .93 \\
\hline $1996-2005$ & 96 & 28 & 1 & & 56 & 16 & 1 & & 40 & 12 & 1 & \\
\hline 2006-2011 & 58 & 15 & $0.95(0.51-1.76)$ & & 41 & 11 & $1(0.47-2.1)$ & & 17 & 4 & $0.88(0.28-2.75)$ & \\
\hline $2012-2017$ & 79 & 18 & $1.11(0.61-2.01)$ & & 72 & 16 & $1.08(0.54-2.18)$ & & 7 & 2 & $1.23(0.26-5.77)$ & \\
\hline
\end{tabular}

EAC, Esophageal adenocarcinoma; $E S C C$, esophageal squamous cell carcinoma; $H R$, hazard ratio; $C I$, confidence interval; $C R T$, chemoradiotherapy; SUVm, maximum standard uptake value; $G E$, gastroesophageal; $S C C$, squamous cell carcinoma; $C R O S S$, carboplatin + paclitaxel; 5-FU, 5-fluorouracil. *Because of the small sample size and limited number of events in the ESCC group, a small subset of clinically relevant variables was selected a priori for univariable analysis. 